\title{
Synthesis and Characterization of a New Family of Iron Porphyrins
}

\author{
Dominik N. Meyer§ and Wolf-D. Woggon* \\ §Mettler Toledo Award Winner (Oral Presentation)
}

\begin{abstract}
A significant tool for better understanding the complex nature of the cofactor of heme thiolate proteins such as Cytochromes P450 is the investigation of model compounds. In this context a new family of iron porphyrins has been synthesized by replacing the native thiolate ligand for $\mathrm{SO}_{3}{ }^{-}$group coordinating the heme iron.
\end{abstract}

Keywords: Cytochrome P450 · Enzyme models · Iron porphyrins · Monooxygenases · Redox potential

\section{Introduction}

Cytochromes $\mathrm{P} 450$ are heme-thiolate proteins abundant in nature. These mono-oxygenases catalyze diverse reactions significant to the metabolism of xenobiotics as well as to the biosynthesis of important biomolecules [1].

Earlier investigations on iron porphyrin active site analogues carrying a thiolate as the fifth ligand $\left(\mathrm{Fe}(\mathrm{III}) \cdots \mathrm{S}^{-}\right)$[2] revealed a rather negative $\mathrm{E}_{\mathrm{o}}<-600 \mathrm{mV}$ (vs. SCE) in contrast to e.g. $\mathrm{P} 450_{\text {cam }}$, one of the bestknown P450s, displaying $\mathrm{E}_{\mathrm{o}}=-280 \mathrm{mV}$ for the resting state. From more recent $\mathrm{X}$-ray studies of $\mathrm{P} 450_{\text {cam }}$ it could be deduced that this difference is due to $\mathrm{H}$-bonding of the thiolate ligand to amino acid residues of the protein backbone. Taken into account this obviously reduced charge density at sulfur

\footnotetext{
${ }^{*}$ Correspondence: Prof. Dr. W.-D. Woggon University of Basel

Department of Chemistry

St. Johanns-Ring 19

$\mathrm{CH}-4056$ Basel

Tel.: +41612671102

Fax: + 41612671109

E-Mail: wolf-d.woggon@unibas.ch

www.chemie.unibas.ch/ woggon/
}

a set of new enzyme models was conceived carrying a $\mathrm{SO}_{3}^{-}$group as the fifth ligand.

\section{Strategy}

DFT calculations on $\mathrm{SO}_{3}{ }^{-}$coordinated iron porphyrins [3] supported our idea that one of the oxygens of the $\mathrm{SO}_{3}{ }^{-}$indeed coordinates to iron donating a charge of 0.3 instead of 1.0 for $\mathrm{S}^{-}$. Energy-profile calculations further assigned the reactivity of the $\mathrm{SO}_{3}{ }^{-}$system to be very similar to the $\mathrm{Fe}^{\cdots}$. $\mathrm{S}^{-}$- coordination. To improve the stability of the model compounds aromatic substituents were introduced at the oxygen-sensitive meso-positions to prevent $\mu$-oxo dimer formation through steric congestion.

\section{Synthesis}

The synthetic pathway is outlined in the Scheme. From mesitylaldehyde (1) on reaction with pyrrol (2) a light sensitive dipyrromethane 3 was obtained, which underwent cyclization with 2-methoxy-benzaldehyde (4) to form the properly substituted porphyrin ring structure 5 following standard procedures [4]. The latter was deprotected to obtain the free phenol $\mathbf{6}$ as a mixture of atropisomers $(\alpha, \alpha-6$ and $\alpha, \beta-6)$ that interconvert at room temperature. Condensation under diluted conditions with the $\mathrm{S}$ protected 'bridge' 7, which had been prepared according to our own protocol, gave product 8. On treatment with a strong base under oxygen-saturated conditions $\mathbf{8}$ was converted to 9. Intermediates that were not oxidized completely to $\mathrm{SO}_{3}{ }^{-}$under these conditions were collected and separately converted to 9 to increase the yield $(\mathbf{F})$. Final iron insertion gave model compound 10. A 2,6-dichlorophenyl-meso-substituted model 11 was synthesized in a similar fashion starting from 2,6-dichlorobenzaldehyde (12) instead of mesitylaldehyde (1).

\section{Characterization}

The X-ray structure of $\mathbf{1 0}$ (Fig. 1) validates the synthetic procedures and the assumption of one of the oxygens of the $\mathrm{SO}_{3}{ }^{-}$group coordinating to iron. The analysis further shows a slightly strained system with the iron out of plane towards the fifth ligand in agreement with the EPR spectrum displaying g-values characteristic of a high-spin $\mathrm{Fe}^{\mathrm{III}}$ system (toluene, $94 \mathrm{~K}$, g-factor: 5.7).

The UV-Vis spectrum of $\mathbf{1 0}$ exhibits typical iron porphyrin absorptions $\left(\mathrm{CH}_{2} \mathrm{Cl}_{2}\right.$ $\lambda_{\max }: 415 \mathrm{~nm}(100$, Soret) and $511 \mathrm{~nm}(12)$, $580 \mathrm{~nm}$ (3), $691 \mathrm{~nm}$ (2) (Q-bands)).

Cyclovoltammetry (Fig. 2) reveals redox potentials of $\mathbf{1 0}$ and $\mathbf{1 1}$ similar to the resting state of $\mathrm{P} 450$ enzymes (Table). This underlines their value as model compounds in this field. A further advantage of iron complexes with $\mathrm{SO}_{3}^{-}$is the stability relative to $\mathrm{S}^{-}$-coordination under aerobic conditions, which makes their handling much more convenient.

\section{Reactivity}

From spectroscopic data [1] the dominant reactive oxidant in the natural system is claimed to be a $\mathrm{Fe}^{\mathrm{IV}}$-porphyrin radical cation (Cpd I) which is formed from the 


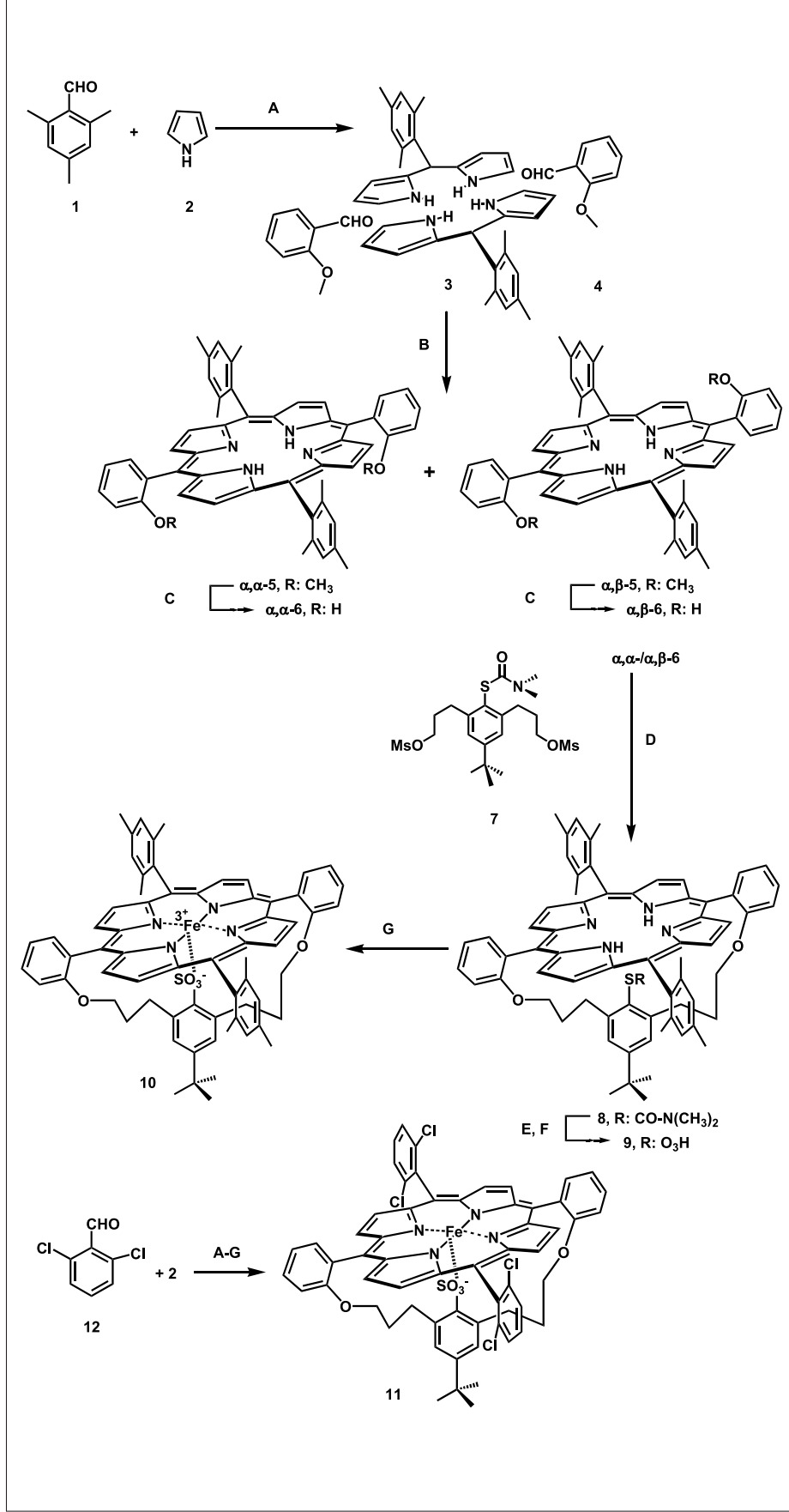

Scheme. Key: A: 0.3 equiv. $\mathrm{BF}_{3} \mathrm{OEt}_{2}, 1 \mathrm{~h}, \mathrm{RT}, 30 \%$; B: 1.8 equiv. TFA, $\mathrm{CH}_{2} \mathrm{Cl}_{2}, 0.5 \mathrm{~h}, \mathrm{RT}$, then 2 equiv. DDQ, $1 \mathrm{~h}$, reflux, 27\%; C: 32 equiv. $\mathrm{BBr}_{3}$, $\mathrm{CH}_{2} \mathrm{Cl}_{2}, 16 \mathrm{~h}, \mathrm{RT}, 79 \%$; D: 30 equiv. $\mathrm{Cs}_{2} \mathrm{CO}_{3}$, DMF, $0.5 \mathrm{~h}, 80{ }^{\circ} \mathrm{C}$ then 1.5 equiv. 7, 4 h, $80^{\circ} \mathrm{C}, 75 \%$; $\mathbf{E}$ : 60 equiv. KOMe, dioxane, $\mathrm{O}_{2}, 16 \mathrm{~h}$, reflux; $\mathbf{F}$ : 2 equiv. $\mathrm{nBu}_{4} \mathrm{NHSO}_{5}, \mathrm{CH}_{2} \mathrm{Cl}_{2}$, 2d, RT, E\&F: 55\%; G: 10 equiv. $\mathrm{FeBr}_{2}$ and 2,6-lutidine, toluene, $1 \mathrm{~h}$, reflux, $86 \%$

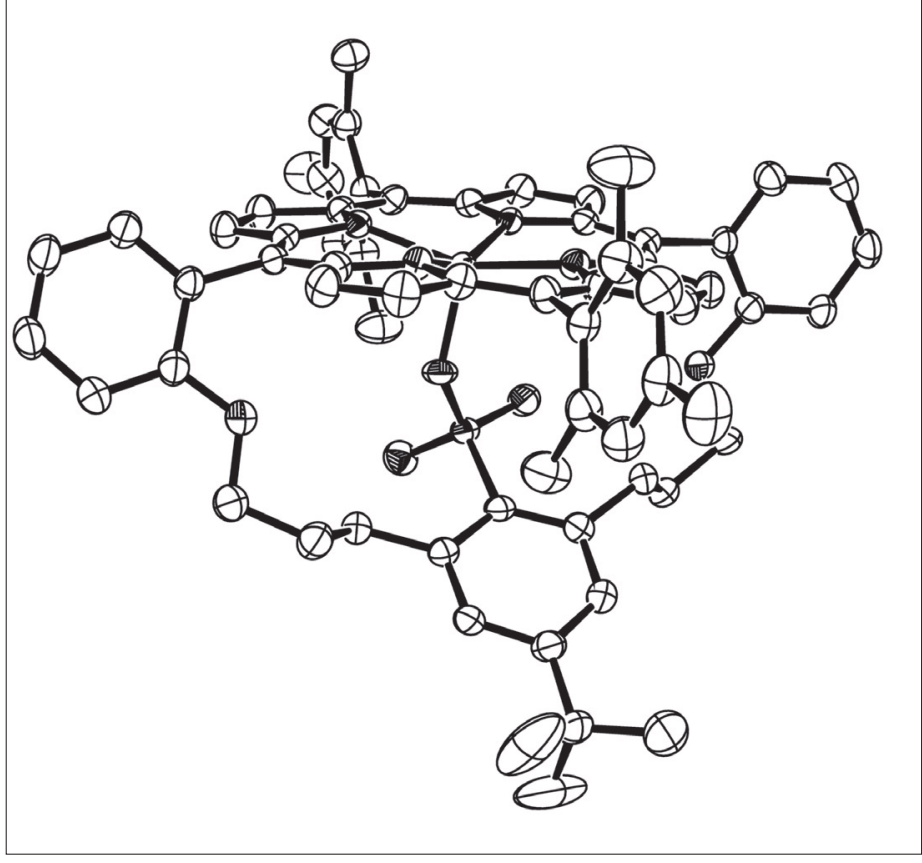

Fig. 1. ORTEP representation of model compound 10

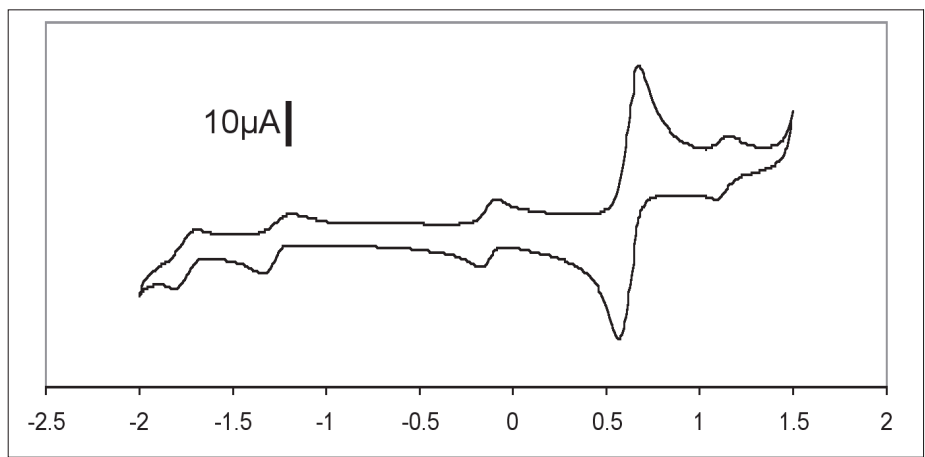

Fig. 2. Cyclovoltammogram of $10(0.6 \mathrm{mM})$ in $0.1 \mathrm{M} \mathrm{LiClO}$, soln. in DMF with ferrocene as an internal standard. Scan rate: $100 \mathrm{mVs}^{-1}$

Table. Redox potentials of two model compounds measured by cyclovoltammetry. The given values (vs. SCE) are calculated from the relative potential to ferrocene used as an internal standard.

\begin{tabular}{|c|c|c|c|c|}
\hline & 1st ox & 1st red & 2nd red & 3rd red \\
\hline 10 & $920 \mathrm{mV}$ & $-340 \mathrm{mV}$ & $-1480 \mathrm{mV}$ & $-1970 \mathrm{mV}$ \\
\hline 11 & $1010 \mathrm{mV}$ & $-280 \mathrm{mV}$ & $-1420 \mathrm{mV}$ & $-1900 \mathrm{mV}$ \\
\hline
\end{tabular}

resting state after substrate binding, reduction, oxygen binding and reductive oxygen cleavage [5].

The $\mathrm{O}=\mathrm{Fe}(\mathrm{IV})$ porph.+ species (Cpd I) can be obtained from $\mathbf{1 0}$ or $\mathbf{1 1}$ on reaction with oxidants such as mCPBA, $\mathrm{PhIO}, \mathrm{H}_{2} \mathrm{O}_{2}$ or certain $\mathrm{N}$-oxides [6]. In that way we obtained UV-Vis spectra (Fig. 3) in agreement with published data for simpler porphyrin systems in the Cpd I - state [6][7].

\section{Outlook}

The synthesis and characterization of a new family of iron porphyrins has been accomplished and assigns them promising capacity as P450 enzyme models. These results are a prerequisite to employ our model compounds for further enzyme-mimetic studies which are currently under investigation. Therein our interest focuses on enzymatic reactions such as epoxidation [3], oxidation of non-activated positions and carbon-carbon bond cleavage. Preliminary results indicate the capability of our model compounds to cleave vicinal diols to the corresponding aldehydes. This reaction represents the last step of the $\mathrm{C}-\mathrm{C}$ bond cleavage in the biotransformation of cholesterol to pregnenolone by P450scc (CYP 11A1) in the mammalian steroid hor- 


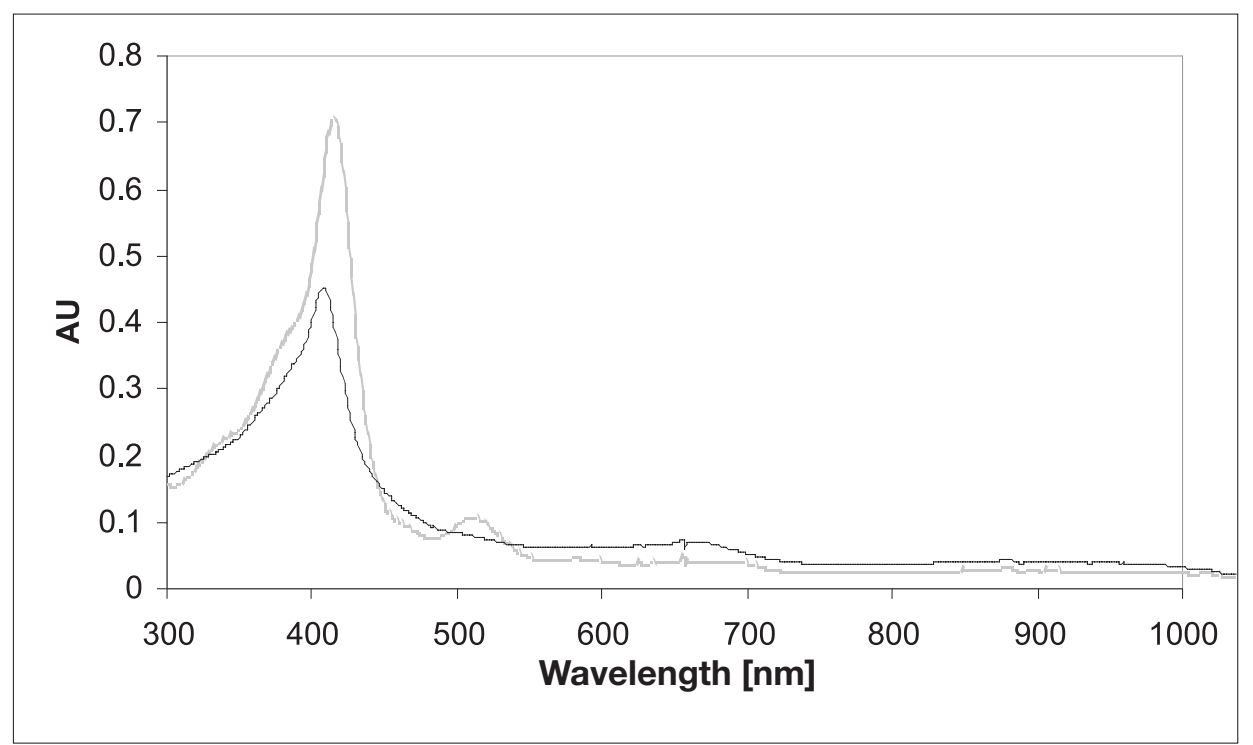

Fig. 3. UV-Vis change after addition of 1.5 equiv. of mCPBA $\left(10 \mu \mathrm{M}, \mathrm{CH}_{2} \mathrm{Cl}_{2},-50{ }^{\circ} \mathrm{C}\right)$, dotted line: spectrum $30 \mathrm{sec}$ after addition, full line: $25 \mathrm{~min}$ after addition

mone biosynthesis [8]. The same reaction sequence is also claimed to be part of other biotransformation processes $e$.g. in the biotin biosynthesis in bacillus subtilis [9].

\section{Acknowledgements}

The authors thank M. Neuburger for crystal structure analysis of 10, L. Sbaragli for synthesis of $\mathbf{1 1}$ and the Swiss National Science Foundation for financial support.

Received: December 13, 2004

[1] P.R. Ortiz de Montellano, in 'Cytochrome P450: Structure, Mechanism and Biochemistry', 2nd ed., Ed. P.R. Ortiz de Montellano, Plenum Press, New York, 1995.

[2] W.-D. Woggon, Chimia 2001, 55, 366.
[3] S. Kozuch, T. Leifels, D. Meyer, L. Sbaragli, S. Shaik, W.-D. Woggon, Synlett $\mathbf{2 0 0 5}$, in press.

[4] B. Stäubli, H. Fretz, U. Piantini, W.-D. Woggon, Helv. Chim. Acta 1987, 70, 1173.

[5] W.-D. Woggon, Top. Curr. Chem. 1997, 184, 39.

[6] R. Weiss, A. Gold, A.X. Trautwein, J. Terner in 'the Porphyrin Handbook', Volume 4, Eds. K. M. Kadish, K. M. Smith, R. Guilard, Academic Press, 2000.

[7] J.T. Groves, Y. Watanabe, J. Am. Chem. Soc. 1988, 110, 8443.

[8] S. Lieberman, Y. Lin, J. Steroid Biochem. Mol. Biol. 2001, 78, 1.

[9] J. Stok, J. De Voss, Arch. Biochem. Biophys. 2000, 384, 351. 